\title{
Numerical simulations of dense water cascading on a steep slope
}

\author{
by Fred Wobus $^{1,2}$, Georgy I. Shapiro ${ }^{1,3}$, Miguel A. M. Maqueda ${ }^{4}$ \\ and John M. Huthnance ${ }^{4}$
}

\begin{abstract}
The sinking of dense shelf waters down the continental slope (or "cascading") contributes to oceanic water mass formation and carbon cycling. Cascading over steep bottom topography is studied here in numerical experiments using POLCOMS, a 3-D ocean circulation model using a terrain-following $s$-coordinate system. The model setup is based on a laboratory experiment of a continuous dense water flow from a central source on a conical slope in a rotating tank. The governing parameters of the experiments are the density difference between plume and ambient water, the flow rate, the speed of rotation and (in the model) diffusivity and viscosity. The descent of the dense flow as characterized by the length of the plume as a function of time is studied for a range of parameters. Very good agreement between the model and the laboratory results is shown in dimensional and nondimensional variables. It is confirmed that a hydrostatic model is capable of reproducing the essential physics of cascading on a very steep slope if the model correctly resolves velocity veering in the bottom boundary layer. Experiments changing the height of the bottom Ekman layer (by changing viscosity) and modifying the plume from a 2-layer system to a stratified regime (by enhancing diapycnal diffusion) confirm previous theories, demonstrate their limitations and offer new insights into the dynamics of cascading outside of the controlled laboratory conditions.
\end{abstract}

\section{Introduction}

\section{a. Dense water cascading}

Dense waters flowing from shelf seas down the continental slope contribute to ocean ventilation and water mass formation (notably in the Antarctic, e.g. Baines and Condie, 1998; Bergamasco et al., 2004; Gordon et al., 2009) and hence ocean circulation (Killworth, 1983). Dense water flows may also contribute to the export of carbon from shelf seas as a component of the "carbon pump" (e.g. Holt et al., 2009). This is illustrated by the appearance of chlorophyll at $500 \mathrm{~m}$ down the slope as the clearest evidence of the Malin shelf cascade

1. School of Marine Science and Engineering, University of Plymouth, Drake Circus, Plymouth, PL4 8AA, United Kingdom.

2. Corresponding author.email: fred.wobus@plymouth.ac.uk

3. P. P. Shirshov Institute of Oceanology, Russian Academy of Sciences, 36, Nahimovski, Prospect, Moscow, 117997, Russia.

4. National Oceanography Centre, Joseph Proudman Building, Liverpool, L3 5DA, United Kingdom. 
(Hill et al., 1998), the export of particulate matter down the slope of northern Biscay (Wollast and Chou, 2001) and preferentially down canyons in the western Mediterranean (e.g. Sánchez-Vidal et al., 2008). In the Arctic Ocean there is growing understanding of the influence of cascading on the formation and maintenance of the halocline and on the global overturning circulation (Aagaard et al., 1981; Melling and Lewis, 1982; Rudels et al., 1996; Steele and Boyd, 1998; Rudels et al., 1999; Carmack, 2000; Furevik et al., 2007; Rudels, 2009; Turner, 2010). Despite some recent estimates (Ivanov et al., 2004), the role of cascading in the Arctic Ocean remains largely unquantified. Regarding the modeling of cascading, Furevik et al. (2007) state that "Shelf processes and down slope sinking of waters is generally poorly described in climate models, and there is therefore little knowledge on how this will change in a future climate." The aim to improve the representation of cascading by models has motivated the present study.

As steep slopes and geostrophy combine to inhibit shelf-ocean exchange (Huthnance, 1995) there is considerable interest in processes that result in velocity veering and break the geostrophic constraint to facilitate cross-slope flow. Cascading is one such process on account of the importance of (turbulent) friction. It occurs where dense water - formed by cooling, evaporation or ice-formation with brine rejection over the shallow continental shelf - spills over the shelf edge and descends the continental slope as a near-bottom gravity current. During its descent, the plume is modified by mixing and entrainment, and detaches off the slope when reaching its neutral buoyancy level (Lane-Serff, 2009).

Cascading (or at least its outcome) has been widely observed (Ivanov et al., 2004), especially around the Arctic Ocean (Schauer and Fahrbach, 1999; Ivanov and Golovin, 2007; Geyer et al., 2009), the Antarctic (Bergamasco et al., 2004; Orsi and Wiederwohl, 2009) and the western Mediterranean (Salat et al., 2002; Sánchez-Vidal et al., 2008; Canals et al., 2009). There has also been significant progress in describing its physical properties (Griffiths, 1986). Shapiro and Hill (1997) developed a $1 \frac{1}{2}$-layer model with bottom friction, interfacial Ekman veering and entrainment; it lies between "stream-tube" models (Smith, 1975) and full 3-D models. A classification of cascades is provided in Shapiro et al. (2003). The form of bottom boundary layer acceleration when the density gradient and bottom slope exceed a threshold is analyzed in Huthnance (2009).

Despite its demonstrated effect on water mass formation and carbon cycling, cascading is poorly represented in modern climate models. As cascading occurs in the near-bottom layer, it poses a challenge for 3-D models of any extensive area owing to the fine resolution required. There are unresolved questions of parameterizing turbulent mixing and entrainment in the bottom boundary layer (Lane-Serff, 2009). Progress in the comparison of modeling results to measurements of dense water flows has been made for relatively persistent overflows, notably the Faroe Bank Channel (see Legg et al., 2009, and references therein). Cascading, however, is highly intermittent in space and time and field observations of the process (rather than its outcomes) remain elusive, hence the validation of models against measurements has proved difficult. Instead, laboratory experiments have proved valuable as a test for models of cascading. The influence of the density difference, flow rate and rotation 


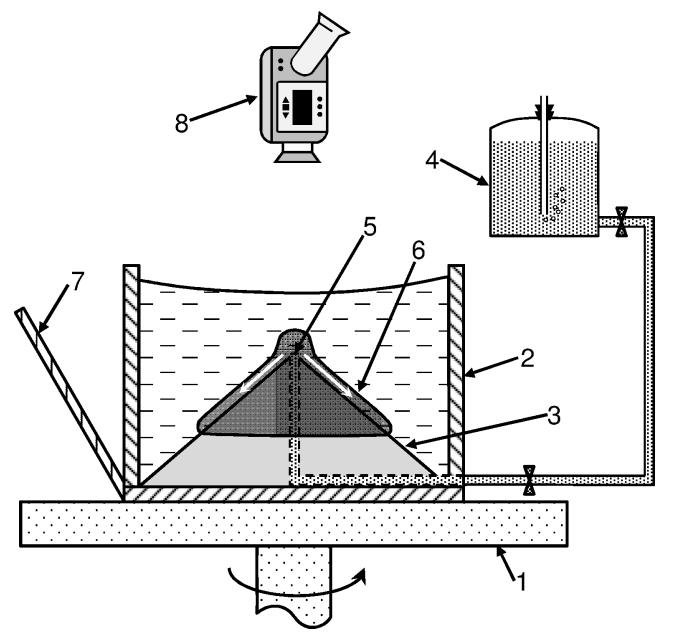

Figure 1. Schematic of the laboratory setup: 1, rotating turntable; 2 , water tank; 3 , cone; 4, Mariotte's bottle; 5 , dense water inflow; 6 , dense water plume; 7 , side-view mirror; 8 , video camera (Adapted from Fig. 1 in Shapiro and Zatsepin, 1997).

rate on the dense water flow has been investigated using rotating tanks with either conical or straight bottom slopes (e.g. Shapiro and Zatsepin, 1997; Etling et al., 2000; Cenedese et al., 2004; Sutherland et al., 2004). In addition to a simple laminar flow regime, several more complex regimes have been observed: roll-waves (Shapiro and Zatsepin, 1997) as well as vortices and eddies (Lane-Serff and Baines, 1998, 2000; Etling et al., 2000).

This paper revisits the laboratory experiments by Shapiro and Zatsepin (1997) by applying a 3-D ocean model to the study of cascading on a steeply-sloping rotating cone. We reproduce the laboratory results to validate the 3-D model and then go beyond the scope of the laboratory experiments. We identify the areas of applicability of the previously developed simplified theories of cascading and explore the Ekman dynamics in the frictional boundary layer. We also investigate parameters and regimes which are difficult to create in the laboratory and are challenging to analyze with simplified theories.

\section{b. Laboratory studies and reduced physics theory}

The laboratory experiments carried out by Shapiro and Zatsepin (1997), hereafter referred to as SZ97, consisted of a solid cone placed in a tank mounted on a rotating turntable (Fig. 1). The tank $(50 \times 50 \times 46 \mathrm{~cm})$ was filled with a homogeneous water solution while dense water was injected at the tip of the cone, which then propagated downward along the wall of the cone. The dense water was colored so the spread of the plume could be observed using a video camera (Fig. 1).

The geometry of a cone has a number of advantages over a straight slope. A cone simulates a virtually endless slope along which the downslope velocity can be studied for long periods of time without the plume reaching any lateral boundary. This avoids the requirement for 
a large domain and possible complications with lateral boundary conditions in numerical experiments.

The main experimental parameters were the reduced gravity $g^{\prime}$, the flow rate $Q$ and the Coriolis parameter $f$. The density difference represented by $g^{\prime}$ was created by mixing in varying amounts of salt into the inflowing water. The Coriolis parameter $f$ was varied by different rotation speeds of the turntable. The flow rate $Q$ was regulated by a valve connected to a Mariotte's bottle. SZ97 observed limited mixing only in the region around the cone tip where a bulbous dome forms over the inflow. Diapycnal mixing between the ambient and injected fluids was not observed outside of this region near the inflow. The propagation of the plume was described using a simplified theory of cascading.

It is known that if the effects of friction are negligible, a steady-state gravity current in a rotating framework would simply flow along contours of constant depth. The reference alongslope velocity referred to hereafter as the Nof speed (Nof, 1983) is given by Eq. (1):

$$
V_{\text {Nof }}=\frac{g^{\prime}}{f} \tan \theta
$$

where $f$ is the Coriolis parameter and $\theta$ is the slope angle. The reduced gravity $g^{\prime}$ is defined as $g^{\prime}=g \frac{\Delta \rho}{\rho_{0}}$, where $g$ is the acceleration due to gravity, $\Delta \rho$ is the density difference between the dense water and ambient water, and $\rho_{0}$ is the ambient density.

Downslope motion of dense water is facilitated by forces, such as friction with the bottom or at the interface between the plume and the ambient water, that break the constraints of potential vorticity conservation. Friction brings the flow velocity to zero at the bottom, the viscosity of the fluid propagates its effects into the flow, while at some distance from the bottom the Coriolis force dominates in the interior of the flow over the diminishing frictional force. This creates a thin boundary layer of the order of the Ekman depth, which arises as a key height scale for the bottom boundary layer. Accounting for the slope angle $\theta$ we define the Ekman depth $H_{e}$ as:

$$
H_{e}=\sqrt{\frac{2 \nu}{f \cos \theta}}
$$

where $v$ is the vertical viscosity.

Shapiro and Hill (1997), hereafter referred to as SH97, studied gravity currents in a rotating framework using a $1 \frac{1}{2}$-layer model, which assumed a homogeneous layer of dense water overlaid by a homogeneous upper layer of ambient water. In contrast to "streamtube" or "slab" models (Smith, 1975; Killworth, 1977; Price et al., 1993) which assumed a vertically uniform velocity distribution within the plume, the velocity structure in SH97 is fully three-dimensional. Compared to full physics 3-D numerical models, the SH97 model assumes a simplified density structure and hence belongs to a class of 'reduced physics' models.

SH97 presented a solution for the horizontal velocity profiles in a two-layer fluid (for a detailed derivation, see Shapiro and Hill, 2003, Appendix A). Their solution describes 
a veering of velocity similar to the 'classic' Ekman spiral. This 'modified' Ekman spiral, however, includes the interfacial Ekman layer which enhances downslope transport and incorporates additional velocity veering at the boundary between dense and ambient water.

SH97 showed that in the special case of steady state cascading over a plane slope with no entrainment and no upper layer flow the plume height cannot exceed $h_{f}=1.78 \times H_{e}$. In this case, the downslope velocity can be expressed as a fixed fraction $\left(u_{F}=0.2 V_{N o f}\right)$ of the alongslope velocity, meaning that the lower edge of the plume crosses the isobaths at a constant angle. A different approach was taken by Killworth (2001), who parameterized the rate of descent based on an energy equilibrium solution as $\frac{d D}{d s}=\frac{1}{400}$ where $D$ is a downslope bathymetric variable and $s$ is the along-stream variable.

SZ97 adapted the SH97 model to a gravity current flowing down a conical slope. This version of the model was formulated in a curvilinear rotating orthogonal coordinate system, set the entrainment velocity to zero and used nondimensional variables. Here we follow precisely the nondimensionalization scheme introduced by SZ97 (see therein for details): $L_{0}$ as a horizontal length scale of the dense water plume, $T_{0}$ as the time scale (Eq. (3)), the Ekman depth $H_{e}$ (Eq. (2)) as the vertical height scale and $V_{N o f}$ (Eq. (1)) as the scale for velocities in the downslope and alongslope direction.

$$
L_{0}=\frac{Q}{2 \pi \cos \theta V_{N o f} \sqrt{2} H_{e} G_{m}}, \quad T_{0}=\frac{\sqrt{2} L_{0}}{V_{N o f}}
$$

where $G_{m} \cong 1.12$ is a numerical constant.

The length scale $L_{0}$ is therefore proportional to $Q /\left(V_{N o f} H_{e}\right)$, i.e. proportional to the length of the plume from tip to front and suitably scales with the flow rate $Q$ while $H_{e}$ and $V_{N o f}$ are the 'natural' scales for the plume height and velocities, respectively.

In Section 3 we use this nondimensionalisation scheme to compare results from the "full physics" model with the "reduced physics" model and the laboratory experiments.

\section{Methods}

\section{a. Numerical model description and geometry}

The numerical model used here is the Proudman Oceanographic Laboratory Coastal Ocean Modeling System (POLCOMS). POLCOMS is a finite difference ocean model that uses the incompressible, hydrostatic and Boussinesq approximations (Holt and James, 2001). The model uses a horizontal B-grid discretization, which ensures an accurate representation of the Coriolis force. In the vertical, POLCOMS uses a terrain-following coordinate whose resolution is a function of depth ( $s$-coordinate), so that the number of vertical levels can be enhanced near the top and bottom boundaries of the domain. For computational efficiency, POLCOMS splits the equations into a fast barotropic component and a slow baroclinic component. The barotropic component solves the depth independent part of the equations. It includes a fully nonlinear free surface formulation that guarantees exact conservation of fluid volume and permits the injection of dense fluid into the system. The 
model's ability to accommodate changes in volume is crucial for the reproduction of the laboratory experiments described below. To improve the accuracy of horizontal pressure gradients in the presence of steep bathymetric slopes, such as those in our experiments, hydrostatic pressures are calculated by interpolation of the buoyancy field onto horizontal planes through velocity points. Fluid transports are evaluated using the Piecewise Parabolic Method, which creates significantly less numerical diffusion and dispersion than ordinary advection schemes and helps, thus, to preserve sharp property gradients and boundaries, as is required in our cascading experiments.

POLCOMS was designed as a regional ocean model for the study of coastal and shelf processes and has been extensively used and validated for the European continental shelf and the northeast Atlantic, most recently by Holt and James (2006) and Wakelin et al. (2009), and other regions such as the Black Sea (Enriquez et al., 2005) and the Mediterranean Sea (Bolaños et al., 2007). The version of POLCOMS used in this study was modified to be used under the Windows operating system (Enriquez et al., 2005).

The model bathymetry was set up with a cone of the original dimensions (radius $r=$ $25 \mathrm{~cm}$, inclination angle $\theta=39^{\circ}$ ). The base of the 'tank' was extended by $10 \mathrm{~cm}$ to avoid boundary complications when the plume reaches the bottom of the cone. The height of the tank was slightly reduced to $32 \mathrm{~cm}$, leaving a depth of $12 \mathrm{~cm}$ at the cone tip.

\section{b. Model parameters}

The horizontal grid resolution was chosen to be $\Delta x=5 \mathrm{~mm}$ for a $120 \times 120$ grid to sufficiently resolve lateral details of the descending plume. This small horizontal step addresses potential issues with evaluating bottom pressure on a steep slope when the bottom in the adjacent cell (laterally) is displaced by more than one cell in the vertical (Haney, 1991). Time steps for the barotropic and baroclinic components were set to $\Delta t=0.75 \mathrm{~ms}$ and $15 \mathrm{~ms}$, respectively, to satisfy the Courant-Friedrichs-Lewy condition.

The vertical resolution was configured specifically to resolve the physics of Ekman veering in the bottom and interfacial boundary layers. We chose $45 s$-levels (see Fig. 2) and adjusted the vertical coordinate in order to have 10 computational levels within the frictional layer near the injection point. This gives the finest vertical resolution of $\Delta z=0.04 \mathrm{~mm}$ at the bottom near the cone tip and the largest $s$-level spacing $\Delta z=27.1 \mathrm{~mm}$ in the interior at the tank edges.

The standard bottom boundary condition in POLCOMS is the quadratic drag law using an empirical drag coefficient $C_{D}$. Following results by Shapiro and Hill (2003) and Wirth (2009) that proper resolution of the velocity profiles in the frictional layer significantly improves modeling accuracy we attempt here to resolve this layer explicitly. Ekman theory requires that friction against the bottom brings the interior velocity (inside the plume) to zero at the bottom boundary. The model code was therefore changed to a no-slip bottom boundary condition, which, given the fine vertical resolution near the bottom, leads to the development of an Ekman spiral. 


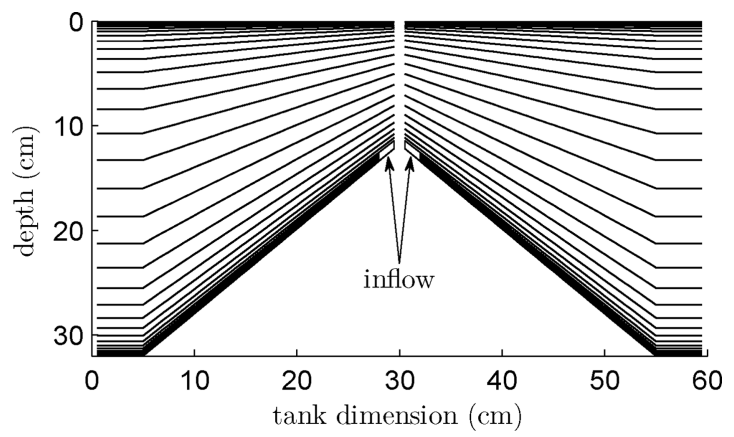

Figure 2. Diagram showing the vertical resolution of the model setup with $45 s$-levels. Arrows indicate the location of the dense water inflow near the top of the cone which extends vertically over 15 $s$-levels.

POLCOMS is used with the semi-implicit scheme for the Coriolis term as it conserves kinetic energy (see Cushman-Roisin and Beckers, 2011, Chapter 2). The model code related to river inputs was adapted to simulate an injection of salty dense water at the cone tip into a circular region around the mid-point of the model domain (highlighted in Fig. 2). The temperature is kept at $20^{\circ} \mathrm{C}$ for inflowing and ambient water, while the density difference characterised by $g^{\prime}$ is simulated by varying the salinity of the inflowing water.

Our modeling experiments can be grouped into two sets. In the first set of runs we simulate the laboratory conditions by using molecular values of diffusivity and viscosity to validate the model and compare its results to the original laboratory experiments. In a second set of runs we increase the values of either viscosity and diffusivity, or both, to observe the response of the flow to changes in the Ekman depth and investigate the behavior of a sinking plume with a diffuse (i.e. density stratified) interface, as those latter runs simulate the effects of enhanced mixing. In all experiments we chose to use a constant value of viscosity $v$ and diffusivity $\kappa$ throughout the model domain.

In the first set of numerical experiments we simulate the nonturbulent (laminar) nature of the flow observed in the laboratory. The viscosity was not measured in the original laboratory experiments and SZ97 assumed a reference value for molecular viscosity $(\nu \approx$ $\left.10^{-6} \mathrm{~m}^{2} \mathrm{~s}^{-1}\right)$. We use a slightly higher value $\left(\nu=2 \times 10^{-6} \mathrm{~m}^{2} \mathrm{~s}^{-1}\right)$ for those model runs comparing the 3-D model to the laboratory experiments (see Table 1) to account for possible impurities in the tap water that was originally used in the laboratory. At oceanic scales there is no appreciable difference between the diffusivity of heat and salt due to turbulence, while at laboratory scales, when molecular processes are significant, they differ by approximately 2 orders of magnitude. In the first set of experiments, the values for the horizontal and vertical diffusivity are based on a reference value for the molecular diffusivity of salt in sea water $\left(\kappa=1.3 \times 10^{-9} \mathrm{~m}^{2} \mathrm{~s}^{-1}\right)$ as the density difference in all our experiments is created by salt alone. The resulting Prandtl Number in the horizontal and vertical is $\operatorname{Pr}_{h}=\operatorname{Pr}_{v}=\frac{v}{\kappa}=1538$. 
Table 1. Summary of model parameters used in validation (Section 3a) and comparison runs (Section 3c), in experiments that vary the Ekman depth (Section 3d) and experiments with a stratified plume interface (Section 3e).

\begin{tabular}{lcccc}
\hline Parameter & Validation & Comparison & Ekman depth & Stratified plume \\
\hline $\mathrm{f}\left(\mathrm{s}^{-1}\right)$ & 1.6 & $1.0-4.1$ & 1.6 & 1.6 \\
\hline $\mathrm{Q}\left(\mathrm{cm}^{3} \mathrm{~s}^{-1}\right)$ & $0.3-5.0$ & $0.3-7.4$ & $1.7-3.7$ & $1.6-2.1$ \\
\hline$g^{\prime}\left(\mathrm{cm} \mathrm{s}^{-2}\right)$ & $0.4-4.2$ & $0.3-9.0$ & $1.2-1.7$ & $1.5-1.7$ \\
\hline$\kappa\left(\mathrm{m}^{2} \mathrm{~s}^{-1}\right)$ & $1.3 \times 10^{-9}$ & $1.3 \times 10^{-9}$ & $1.3 \times 10^{-9}$ & $10^{-9}-10^{-5}$ \\
\hline$\nu\left(\mathrm{m}^{2} \mathrm{~s}^{-1}\right)$ & $2 \times 10^{-6}$ & $2 \times 10^{-6}$ & $10^{-6}-10^{-4}$ & $2 \times 10^{-6}\left(10^{-6}-10^{-5}\right)$ \\
\hline$H_{e}(\mathrm{~cm})$ & 0.179 & $0.112-0.227$ & $0.127-1.27$ & $0.179(0.127-0.4)$ \\
\hline$P r_{v}$ & 1538 & 1538 & $769-76923$ & $2000-0.2(1-0.1)$ \\
\hline
\end{tabular}

In the second set of numerical experiments we simulate conditions that were not created in the laboratory. To examine the response of the plume to changes in the Ekman depth $H_{e}$, we modify the vertical viscosity from $v=10^{-6}$ to $10^{-4} \mathrm{~m}^{2} \mathrm{~s}^{-1}$ (Section $3 \mathrm{~d}$ ). In these runs the Prandtl Number in the horizontal remains unchanged $\left(P r_{h}=1538\right)$, but in the vertical we get $P r_{v}=769$ to 76900 . In model runs that investigate the effects of a diffuse interface (see Section 3e), we create a smooth transition between plume and ambient water by modifying the vertical diffusivity in the model from $\mathrm{\kappa}=10^{-9}$ to $10^{-5} \mathrm{~m}^{2} \mathrm{~s}^{-1}$. In these runs the vertical Prandtl Number varies from $\operatorname{Pr}_{v}=2000$ to 0.2. Further experiments are conducted for a plume with a stratified interface at $\kappa=10^{-6} \mathrm{~m}^{2} \mathrm{~s}^{-1}$ by varying the viscosity from $v=10^{-6}$ to $10^{-5} \mathrm{~m}^{2} \mathrm{~s}^{-1}$, resulting in a Prandtl Number of $\operatorname{Pr}_{v}=1$ to 0.1 . The latter experiments which investigate a plume with a stratified interface (Section 3e) where $\operatorname{Pr}_{v}=O(1)$ are thought to be the most representative of oceanic conditions where diffusion of momentum (viscosity), heat and salt are all of the same order due to turbulence. Table 1 summarizes the model parameters for our experiments.

In keeping similar conventions to the laboratory observations by SZ97 we divide the modeled flow into 3 zones (Fig. 3a). In the injection zone near the inflow, fluid is trapped and a bulbous dome develops (see also Figs. 4e and 4f). The second zone is the viscous flow forming the main part of the cascade where the dominating balance of forces is between friction, buoyancy and the Coriolis force. Our profiles of salinity and velocity structure are sampled in this zone at a downslope distance of $r_{s}$. The bulging plume head forms the third zone. We do not attempt to discuss the exact limits of these zones objectively, as POLCOMS covers all of them. Instead, we merely make sure that $r_{s}$ always falls within the main zone (i.e. zone 2 in Fig. 3a) of the flow.

For quantitative analysis of the cascade downslope velocity we measure the length of the plume $L_{f}$ (from the cone tip to the head of the plume) as a function of time $t$ (Fig. 3a). $L_{f}$ is derived from the model output in $1 \mathrm{~s}$ intervals as an average downslope radius of the axisymmetric area covered by dense water in the bottom $s$-level. 

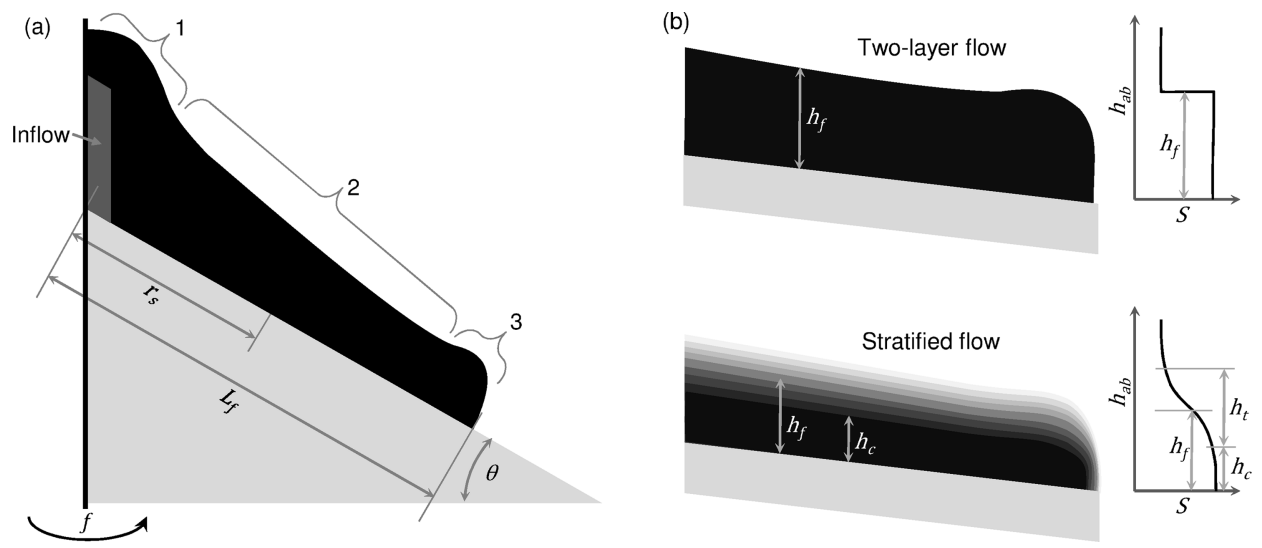

Figure 3. Schematics of the modeled flow and the measured variables. (a) Cross-section of an idealized flow on a slope with angle $\theta$. The downslope length of the plume is measured as $L_{f}$, while the plume height, salinity and velocity profiles are sampled at a downslope distance $r_{s}$. The flow is divided into these zones: 1 , injection zone forming a bulbous dome over the inflow at the cone tip; 2 , main viscous flow; 3 , plume head. (b) The two types of flows with an idealised profile of salinity $(S)$ against height above bottom $\left(h_{a b}\right)$ showing how the flow height $h_{f}$, the height of the plume core $h_{c}$ and the height of the transitional layer $h_{t}$ are measured.

We differentiate between two main flow regimes: a 2-layer flow and a stratified flow (Fig. 3b). Low values of diffusivity reduce diapycnal mixing and maintain a sharp interface between the dense flow and the ambient water in a 2-layer flow. High values of diffusivity, on the other hand, cause the plume interface to become blurred and a density-stratified transitional layer is observed. The height of the flow $h_{f}$ is measured in the vertical as the height above the bottom where the salinity is the mean between the salinity of the cascading and the ambient water. We define the two regimes by comparing the height of the flow $h_{f}$, the height of the transitional layer $h_{t}$, the height of the plume core $h_{c}$ and the Ekman depth $H_{e}$. A 2-layer regime is a flow with a sharp interface where the transitional layer is thinner than the plume core $\left(\frac{h_{t}}{h_{c}} \leqslant 1\right)$ and thinner than the Ekman depth. A stratified flow with a 'blurred' interface has a transitional layer that is thicker than the plume core $\left(\frac{h_{t}}{h_{c}}>1\right)$. In Section 3e we will show that both plume and transitional layer may be considerably thicker than the Ekman depth in a stratified flow.

\section{Results and analysis}

\section{a. Validation of the model against laboratory experiments}

The POLCOMS model (see Section $2 \mathrm{~b}$ ) was run for a range of values of the governing parameters $f, Q$ and $g^{\prime}$ similar to those in the laboratory experiments (see Table 1) and two different versions of the bottom boundary condition: a "slip" bottom boundary condition with the quadratic drag law $\left(C_{D}=0.005\right)$ and a no-slip bottom boundary condition 

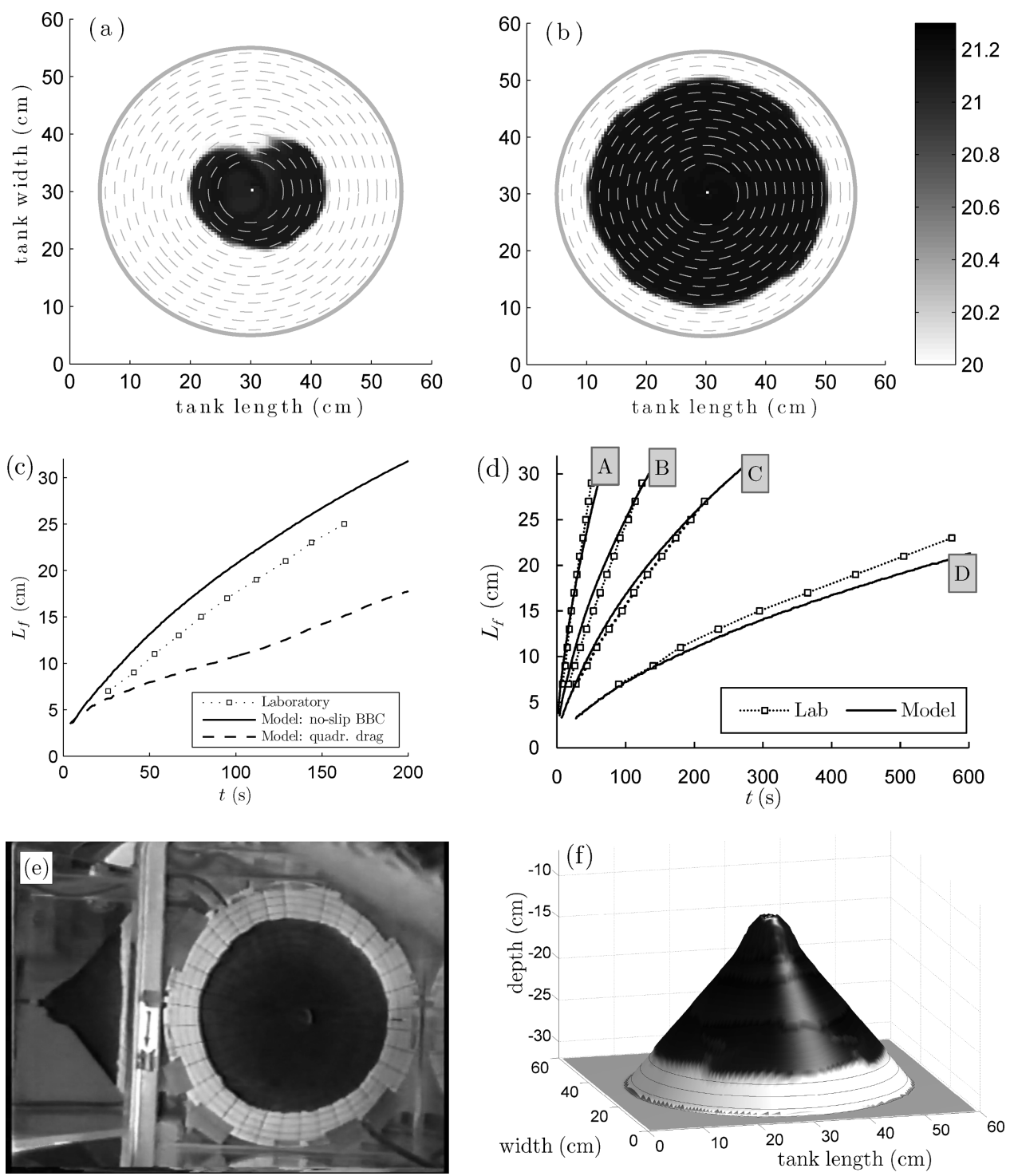

Figure 4. (a) - (c) Model output using different bottom boundary conditions for run ' $\mathrm{V}$ ' $\left(f=1.6 \mathrm{~s}^{-1}\right.$, $Q=2.6 \mathrm{~cm}^{3} \mathrm{~s}^{-1}, g^{\prime}=0.8 \mathrm{~cm} \mathrm{~s}^{-2}$ ). Plume salinity (shaded) after $145 \mathrm{~s}$ - (a) quadratic drag law and (b) no-slip bottom boundary condition - and (c) downslope plume speed (length of the plume $L_{f}$ as a function of time $t$ ) in both runs compared to the matching laboratory experiment. (d) (f) Validation of model to laboratory experiments using runs with a no-slip bottom boundary condition - (d) downslope plume speed for additional model validation runs using a range of governing parameters $f\left(\mathrm{~s}^{-1}\right), Q\left(\mathrm{~cm}^{3} \mathrm{~s}^{-1}\right), g^{\prime}\left(\mathrm{cm} \mathrm{s}^{-2}\right)$ : [A] 1.6, 5.0, 4.2; [B] 1.6, 2.0, 3.4; [C] $1.6,2.0,0.4$; [D] 1.6, 0.3, 0.5. (e) video snapshot of the lab footage and (f) 3-D rendering of plume salinity after $145 \mathrm{~s}$ for run ' $\mathrm{V}$ '. 
similar to that used in the derivation of the equations for the bottom Ekman spiral. Additionally we inspected the original video footage of the laboratory experiments (courtesy of Andrei G. Zatsepin, see Fig. 4e for a screen shot) to validate POLCOMS qualitatively and quantitatively.

The effects of the different bottom boundary conditions are shown in Figures $4 \mathrm{a}$ to $4 \mathrm{c}$ for run 'V' $\left(f=1.6 \mathrm{~s}^{-1}, Q=2.6 \mathrm{~cm}^{3} \mathrm{~s}^{-1}, g^{\prime}=0.8 \mathrm{~cm} \mathrm{~s}^{-2}\right)$. In the run using a "slip" bottom boundary condition with the quadratic drag law the plume eventually disintegrated into wobbling swirls (Fig. 4a); producing results very different from the laboratory experiments. Only the model run using a no-slip bottom boundary condition (Fig. $4 \mathrm{~b}$ ) reproduced the roughly circular plume that was observed in the laboratory (compare with Fig. 4e).

Figure $4 \mathrm{c}$ shows fair quantitative agreement between the laboratory experiment and its matching model run using the no-slip bottom boundary condition (solid line), while the quadratic drag law (dashed line) does not initiate the downslope transport necessary to match the descent speed observed in the laboratory. Hence the runs with the "slip" bottom boundary condition were discarded and are not discussed any further in this paper.

Figures $4 \mathrm{e}$ and $4 \mathrm{f}$ show the same experiment ' $\mathrm{V}$ ' as a snapshot (also after $145 \mathrm{~s}$ ) from video footage of the original laboratory experiment and a 3-D rendering of the model output of the run using the same governing parameters. The model setup with a no-slip bottom boundary condition and near-molecular values for $\nu$ and $\kappa$ (see Table 1) was validated against the laboratory experiments in four more numerical runs. These runs are presented in Figure $4 \mathrm{~d}$ as plots of the downslope plume speed (plume length $L_{f}$ as a function of time $t$ ). All validation runs A-D, V show good agreement between laboratory and model results. The results from those runs demonstrate how accurately POLCOMS is able to reproduce the laboratory experiments given identical cone geometry and the appropriate boundary conditions.

The mirrored side-view of the lab experiment (Fig. 4e) shows the formation of the bulbous dome where injected water accumulates before downslope transport is initiated. This feature is reproduced by the model and can be seen in a 3-D rendering of the model output shown in Figure 4f. The simulated injection of dense fluid into the model domain does not only initiate a plume, but also slightly raises the free surface elevation at the injection site near the cone tip (highlighted in Fig. 2 and Fig. 3a). The initial fluid displacement at the start of injection is detectable as concentric surface waves dispersing outward at the wave speed $(c=\sqrt{g H})$. The upward displacement of the ambient water through continued injection also forms a bulge at the surface maintained by geostrophic adjustment. This bulge is responsible for a velocity field with anticyclonic vorticity high above the plume. We will consider the contribution of this velocity component in the following section.

\section{b. Comparison with reduced physics model - velocity profiles}

The result from a validation run in POLCOMS, our 'full physics' 3-D ocean circulation model, was then compared with the simplified SZ97 model - the 'reduced physics' model. 

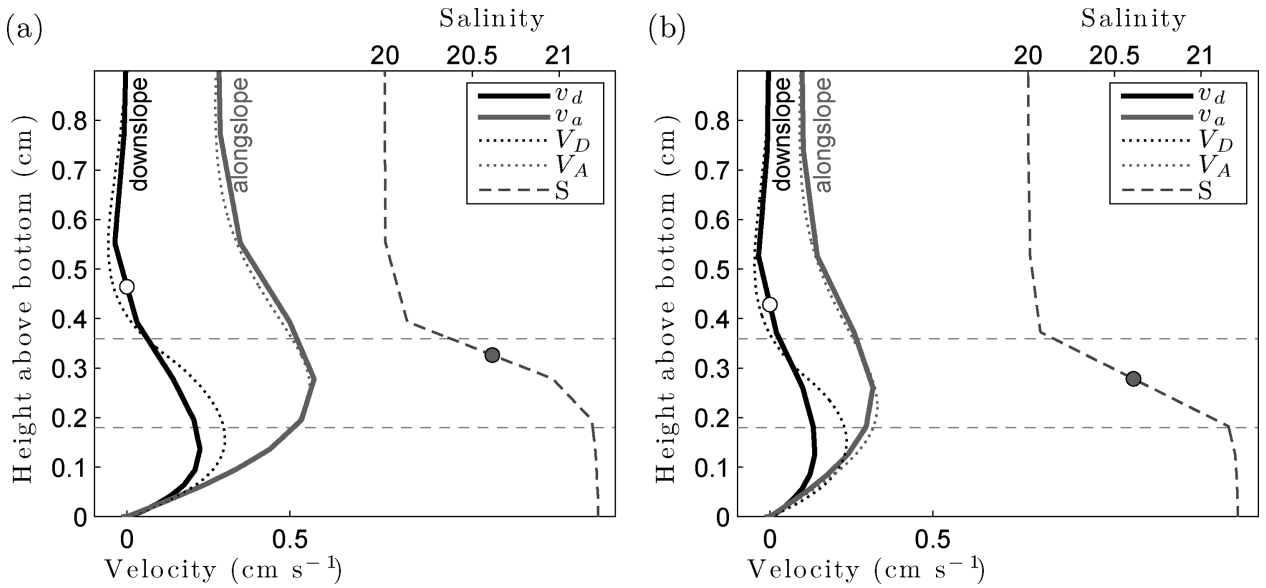

Figure 5. Vertical profiles of velocity ( $v_{d}$ - downslope, $v_{a}$ - alongslope) and salinity for the model run shown in Figures $4 \mathrm{f}$ and $4 \mathrm{~b}$ after (a) $50 \mathrm{~s}$ and (b) $145 \mathrm{~s}$. White circles show layer height of positive downslope velocity. $V_{D}$ and $V_{A}$ show the theoretical profiles for a 2-layer flow. Profiles were sampled at a downslope radius $r_{s}$ when the plume had reached length $L_{f}$ and height $h_{f}$ (grey circle) (relative to the Ekman depth $H_{e}=\sqrt{\frac{2 v}{f \cos \theta}}$ ): (a) $L_{f}=13.1 \mathrm{~cm}, r_{s}=9.8 \mathrm{~cm}$, $h_{f}=1.82 \times H_{e}$; (b) $L_{f}=26.2 \mathrm{~cm}, r_{s}=19.6 \mathrm{~cm}, h_{f}=1.55 \times H_{e}$. The dashed horizontal lines mark the height of $H_{e}$ and $2 \times H_{e}$.

First, we examine the profiles of horizontal velocity and plume salinity which are shown in Figure 5 for model run ' $V$ ' (see Section 3a). The theoretical velocity profiles $V_{D}$ and $V_{A}$ are compared to the modeled velocities $v_{d}$ and $v_{a}$ in the downslope alongslope and direction, respectively. The velocity profiles $V_{D}$ and $V_{A}$ are calculated using Eq. (A7) in Shapiro and Hill (2003) where the ambient velocity $\vec{u}_{0}$ was taken to be equal to the computed velocity at the free surface caused by the bulging surface (this velocity extends throughout the top layer) and the height of the interface $\xi$ was taken to be equal to be the plume height $h_{f}$ (grey circles in Fig. 5).

We examine two panels in Figure 5 at different times in the model run. After $50 \mathrm{~s}$ (Fig. 5a), the salinity shows $h_{f}=1.82 \times H_{e}$. After $145 \mathrm{~s}$ (Fig. 5b), the plume head is approaching the bottom of the cone at which point the plume has spread and doubled the circumference of the front from $82 \mathrm{~cm}$ to $165 \mathrm{~cm}$ leading to a decrease in plume height to $h_{f}=1.55 \times H_{e}$. Despite different geometry and a nonsteady state mode of propagation of the plume, its thickness is not significantly different from the simple estimate obtained by SH97 for a steadystate cascade on a plane slope. The decrease in plume height is a result of the increasing circumference of the plume edge during its downslope descent and is in agreement with the prediction of the SZ97 model which was derived specifically for the conical geometry.

In both snapshots, the modeled alongslope velocity $v_{a}$ compares very well with the SH97 theory, while the downslope velocity $v_{d}$ shows a slight deviation: the return flow is weaker 

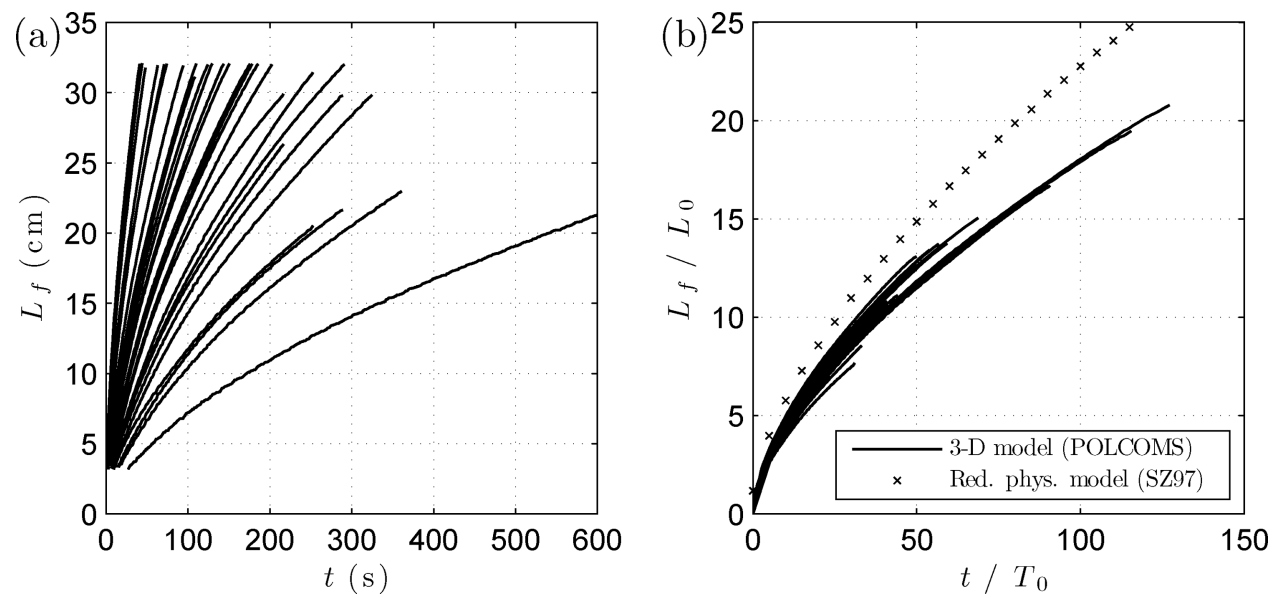

Figure 6. Downslope progression of the plume as a function of time in (a) dimensional and (b) nondimensional variables (scaling given in Eq. (3)) for 29 model runs. The solution of the reduced physics model of Shapiro and Zatsepin (1997) is also shown (as $\times$ ) in (b).

and displaced upward. We attribute this to the departure of the plume interface from the assumption in SH97 of two sharply separated layers. The salinity profiles from the model show a transition between plume and ambient water to suggest some diapycnal mixing and diffusion across the interface, which is not included in the SH97 model. This will be studied in detail in Section 3e.

The maximum downslope velocities in the numerical runs are slightly smaller than predicted by the analytical theory - evident by $v_{d}<V_{D}$. This is not surprising as the theoretical profile $V_{D}$ was obtained for a plane slope assuming sufficient fluid supply at all times. On a conical slope, however, the circumference of the front expands over time thus reducing the available fluid supply to the leading edge which accounts for the reduction in downslope transport over time.

\section{c. Comparison with reduced physics model - plume speed}

Results from 29 numerical runs (including those used for validation in Section 3a) are presented in Figure 6 as plots of the downslope propagation of the plume (plume length $L_{f}$ as a function of time $t$ ) in dimensional and in nondimensional variables. Analyzing the results in dimensional values (Fig. 6a) reveals that the downslope propagation speed is quite scattered between experiments where the governing parameters $f, Q$ and $g^{\prime}$ vary (see Table 1). The reduced physics model, however, predicts that in nondimensional variables using the scales in Eq. (3) all experiments (irrespective of the variations in $f, Q$ and $g^{\prime}$ ) should collapse onto the same line.

Figure $6 \mathrm{~b}$ shows the nondimensionalized downslope propagation of the plume obtained from the SZ97 reduced physics model ( $\times$ symbols) and from the POLCOMS model runs (solid lines). Despite some scatter, the model results collapse onto a curve which 
demonstrates that the nondimensionalization given in Eq. (3), which was derived from the reduced physics model, describes the self-similar nature of the processes reproduced by the full physics model. The SZ97 reduced physics model also captures the slowing of the plume speed over time (as a result of the expansion of the leading edge of the dense front as the plume descends downslope), as already revealed by analysis of the downslope velocities in Section 3b. The two curves from POLCOMS and the reduced physics model in Figure 6b, however, show that the reduced physics model also slightly overestimates the downslope propagation speed. A possible reason for this is that in the 3-D model the density interface is slightly 'less sharp' than it is assumed in a 2-layer model. In Sections $3 \mathrm{~d}$ and $3 \mathrm{e}$ we will simulate conditions in POLCOMS which were not created in the laboratory or included in the reduced physics model to study our validated model under new parameter regimes.

Having in mind that POLCOMS uses the hydrostatic approximation which implies that vertical accelerations are smaller than acceleration due to gravity (Kamenkovich, 1977; Pedlosky, 1987) we compare the magnitude of these accelerations. First, the downslope plume speed is derived as $u_{F}=\frac{d L_{f}}{d t}$, where $L_{f}$ is the plume length shown in Figure 6a. Then, the typical vertical velocity component is estimated as $W=u_{F} \sin \theta\left(\theta=39^{\circ}\right)$ and its acceleration is given by $\frac{d W}{d t}$, which is compared to the reduced gravity $g^{\prime}=\frac{\Delta \rho}{\rho_{0}} g$ (derived from the salinity within the plume). For the runs shown in Figure 6 the ratio of the vertical acceleration to the reduced gravity acceleration is between 0.001 and 0.01 .

\section{d. Comparison with reduced physics model - Ekman depth}

This section examines the response of the cascading plume to changes in the bottom Ekman layer brought about by different values of viscosity. The vertical viscosity affects the height of the frictional boundary layer and thus the Ekman depth $H_{e}$ (see Eq. (2)). According to the reduced physics model, in experiments varying the viscosity $v$ and thus $H_{e}$, (i) the plume height $h_{f}$ should scale with $H_{e}$ (i.e. $h_{f} / H_{e}=$ const), and (ii) the plume speed in nondimensional variables should remain unchanged because the scaling in Eq. (3) includes $H_{e}$.

Figure 7 shows salinity profiles and downslope plume progression plots for a number of runs that vary the vertical viscosity by 2 orders of magnitude from $v=10^{-6}$ to $10^{-4} \mathrm{~m}^{2} \mathrm{~s}^{-1}$ (keeping $\kappa$ constant at $1.3 \times 10^{-9} \mathrm{~m}^{2} \mathrm{~s}^{-1}$ ). The shown salinity profiles (Fig. $7 \mathrm{a}$ ) are averaged over a number of profiles sampled along a circle centered at the cone tip with a sampling radius $r_{s}=0.5 L_{f}$ from model output when the downslope descent of the plume is well developed $\left(15 \mathrm{~cm} \leq L_{f} \leq 20 \mathrm{~cm}\right)$. By comparing averaged salinity profiles we remove any high-frequency fluctuations from the measurements of the plume heights (e.g. ripples along the plume interface).

For the given range in viscosity, the Ekman depth increases 10-fold from $H_{e}=0.127$ to $1.27 \mathrm{~cm}$, and all curves in Figures $7 \mathrm{a}$ and $7 \mathrm{~b}$ should theoretically collapse onto the same line. However, the absolute plume thickness increases from 0.25 to $0.86 \mathrm{~cm}$, but its thickness relative to the Ekman depth $\left(h_{f} / H_{e}\right)$ decreases from $2.0 \times H_{e}$ to $0.7 \times H_{e}$ as successive experiments increase $v$ (see Fig. 7a). The downslope propagation of the plume is shown 

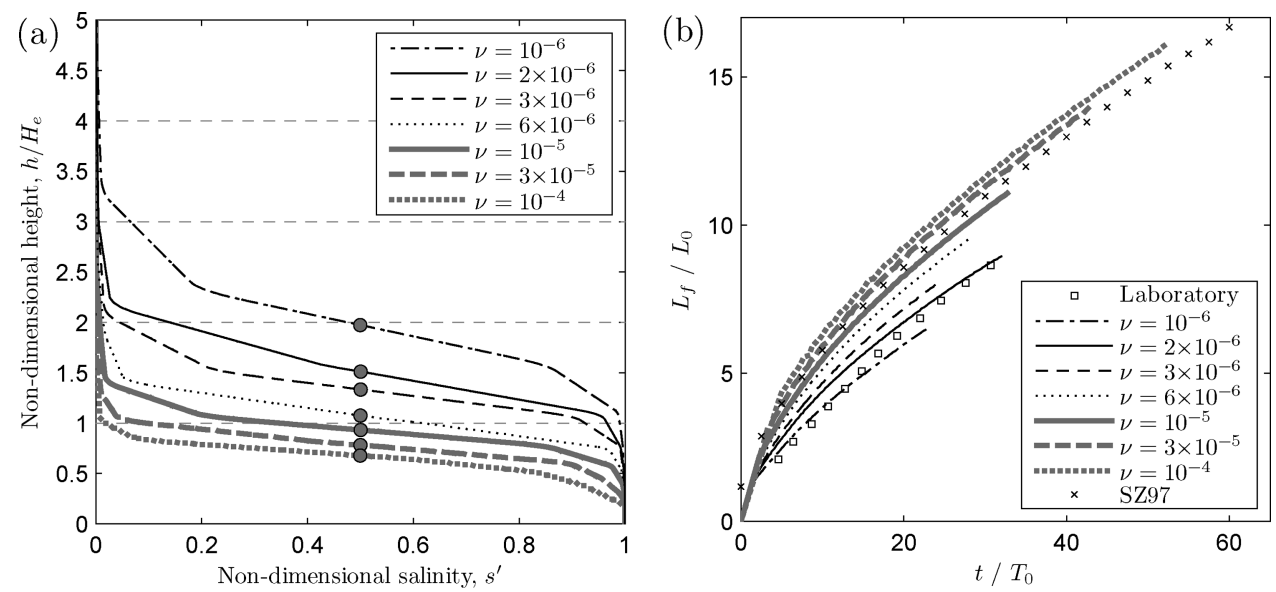

Figure 7. Series of model runs varying the Ekman depth $H_{e}=\sqrt{\frac{2 v}{f \cos \theta}}$ by modifying vertical viscosity $\nu$ (shown in $\left.\mathrm{m}^{2} \mathrm{~s}^{-1}\right)$ : (a) Profiles of non-dimensional salinity $s^{\prime}=\left(S-S_{a m b}\right) /\left(S_{i n j}-\right.$ $S_{a m b}$ ); height above bottom is normalised by the Ekman depth $H_{e}$; circles mark the plume height $h_{f}$ where the salinity crosses $S=\frac{1}{2}\left(S_{i n j}+S_{a m b}\right)$; where $S, S_{i n j}, S_{a m b}$ are the actual salinity and the salinity in injected and ambient fluids respectively. (b) Plume length as a function of time in non-dimensional variables according the scaling in Eq. (3).

in Figure $7 \mathrm{~b}$ as plots of the nondimensional plume length $L_{f} / L_{0}$ as a function of nondimensional time $t / T_{0}$. In this nondimensional framework, the plume advances (relatively) slower in runs with low $\nu$ and faster in runs with high $\nu$. This is because lower viscosity reduces friction and enhances the constraints of geostrophy making it more difficult for the rotating fluid to cross the isobaths (Note that under weak rotation, lower friction leads to a faster descent). On the other hand, increased viscosity also affects plume volume (increase in plume height) and momentum (reduced downslope speed).

The curves in Figure $7 \mathrm{~b}$ collapse to some degree, but not as well as in Figure $6 \mathrm{~b}$ indicating that the 3-D model captures additional dynamics concerning the influence of viscosity on the cascading dynamics which go beyond the SZ97 reduced physics model. However, given the large range of values of $\nu$ the plume propagation still retains properties of a selfsimilar process. Comparisons with the full physics numerical model show that despite the simplifications employed by the reduced physics model it produces reasonable estimates of the main parameters of cascading subject to the plume having a sharp density interface with the ambient water. While it does not fully capture the effects of viscosity, the reduced physics model performs better for a 2-layer flow than in the case of a plume with a blurred interface, which we investigate in the following section.

\section{e. Density stratification at the plume interface}

The reduced physics models, e.g. SH97 and SZ97 as well as the 'streamtube' and 'slab'models by Smith (1975); Killworth (1977); Price et al. (1993) are all based on a 2-layer 

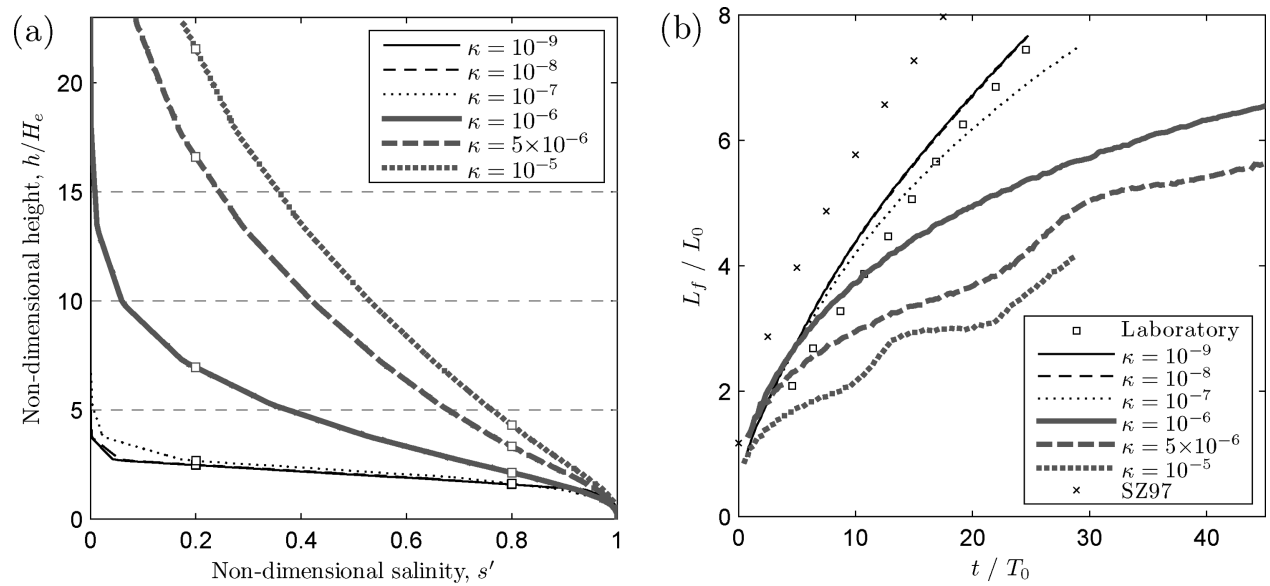

Figure 8. Model runs with sharply separated (thin lines) and stratified plumes (bold lines). A stratified plume interface corresponds to higher values of vertical diffusivity $\kappa$ (shown in $\mathrm{m}^{2} \mathrm{~s}^{-1}$ ). Nondimensionalized (a) salinity profiles (squares indicate height where salinity is $20 \%$ and $80 \%$ of the salinity difference) and (b) plume propagation drawn as in Figure 7.

density structure, where a homogenous plume is overlaid by a homogenous upper layer. While the reduced physics model by SH97 considers a 3-D velocity field and provides a solution for interfacial Ekman veering, it still assumes a sharp density interface between the two fluids. This assumption has proved to be reasonable for cases of weak diapycnal mixing, e.g. observed by Visbeck and Thurnherr (2009). However, in the real ocean there are cases when density stratification in the interfacial layer between the plume and the ambient water is significant (e.g. Girton and Sanford, 2003). This regime was not investigated in the SZ97 laboratory experiments and is not included in the reduced physics model. Unfortunately there is no simple analytical model for the stratified Ekman layer (McWilliams et al., 2009) and we therefore use the numerical model POLCOMS to investigate the behaviour of the cascading plume in the absence of a sharp interface.

A stratified interface could be simulated in a number of ways. In this study we employ the method of increasing the value of vertical diffusivity $\kappa$ to simulate the effects of enhanced diapycnal mixing which smoothes the sharp interface and maintains a stratified flow. In a series of model runs we modify the vertical diffusivity from $\kappa=10^{-9}$ to $10^{-5} \mathrm{~m}^{2} \mathrm{~s}^{-1}$ simulating different degrees of stratification. The degree of stratification is assessed by measuring the thickness $h_{t}$ of the transition zone (Fig. 3b) where salinity ranges from $20 \%$ to $80 \%$ of the total salinity difference between the plume and the ambient water (marked by squares in Fig. 8a), while the height of the plume core $h_{c}$ is defined by a plume salinity $\geqslant$ $80 \%$ of the inflow salinity. We consider the regime a stratified flow with a 'blurred' interface when $\frac{h_{t}}{h_{c}}>1$.

Salinity profiles for the runs with different diffusivities $\kappa$ are presented in Figure 8a. Model runs where $\kappa=10^{-9} ; 10^{-8}$ and $10^{-7} \mathrm{~m}^{2} \mathrm{~s}^{-1}$ produce a plume with a sharp interface 

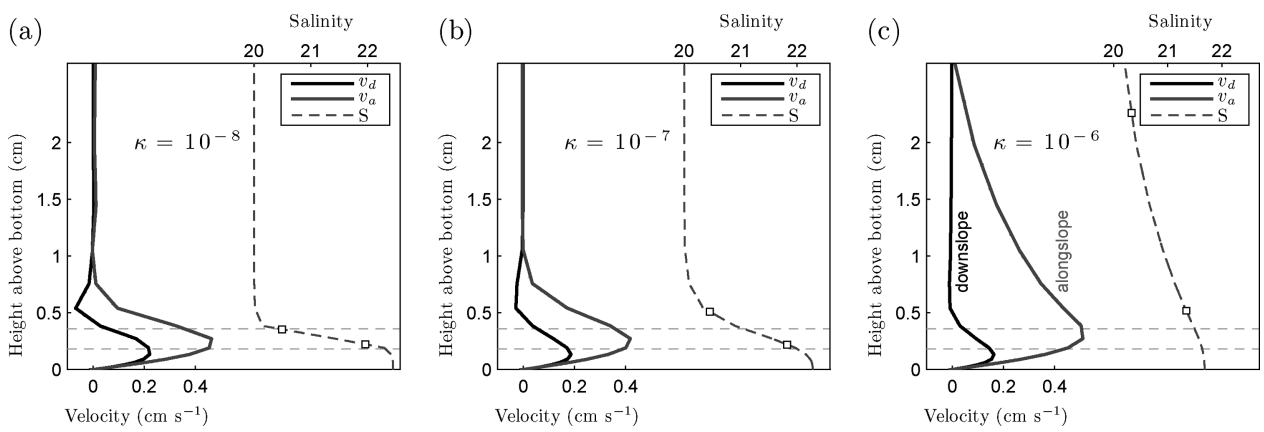

Figure 9. Downslope and alongslope velocity as well as salinity for runs with increased diffusivity $\kappa$ (shown in $\left.\mathrm{m}^{2} \mathrm{~s}^{-1}\right)$. Profiles were sampled in the middle of a fully developed plume $\left(L_{f}=18 \mathrm{~cm}\right.$, $r_{s}=9 \mathrm{~cm}$ ) after (a) $73 \mathrm{~s}$, (b) $81 \mathrm{~s}$ and (c) $216 \mathrm{~s}$. The dashed horizontal lines mark the height of $H_{e}$ and $2 \times H_{e}$.

$\left(\frac{h_{t}}{h_{c}}=0.56 ; 0.57\right.$ and 0.65 , and $\operatorname{Pr}_{v}=\frac{v}{\kappa}=2000 ; 200$ and 20 respectively), while $\kappa=10^{-6}$; $5 \times 10^{-6}$ and $10^{-5} \mathrm{~m}^{2} \mathrm{~s}^{-1}$ show a blurred interface with significant stratification $\left(\frac{h_{t}}{h_{c}}=2.26\right.$; 3.98 and 4.00, and $\operatorname{Pr}_{v}=2 ; 0.4$ and 0.2 respectively). We conclude that the transition between the flow regimes occurs when the Prandtl number in the vertical is approximately unity, i.e. we observe a 2-layer flow with a 'sharp' interface at $P r_{v} \gg 1$ and a stratified flow with a 'blurred' interface at $P r_{v} \leqslant 1$.

The downslope progression of the plume is shown in Figure $8 \mathrm{~b}$ by the nondimensional plume length $L_{f} / L_{0}$ versus nondimensional time $t / T_{0}$. In runs with a sharp interface (thin lines) the plume propagation speed follows a similar same curve as the laboratory experiment and shows some agreement with the SZ97 reduced physics model, while the flow with a stratified interface (bold lines) deviates significantly from the reduced physics theory. In model runs with higher diffusivities but the same viscosities the downslope speed of the plume is reduced. At very high diffusivity $\left(\kappa=10^{-5} \mathrm{~m}^{2} \mathrm{~s}^{-1}\right.$, gray dotted line in Fig. 8b) the plume propagation is very irregular. In this case the downslope flow nearly stops as most of the inflowing dense water gets mixed upward into the water column and the plume breaks up into swirls and eddies.

The velocity structure is also different between runs with sharp and diffuse plume interfaces. Figure 9 shows the velocity profiles for 3 runs $\left(\kappa=10^{-8}\right.$ to $\left.10^{-6} \mathrm{~m}^{2} \mathrm{~s}^{-1}\right)$ that characterize this transition (left to right) from a 2-layer system to a stratified interface. With increasing diffusivity, it takes longer for the plume to develop and initiate the downslope descent. The profiles are therefore sampled from the model output at an equal downslope distance of $r_{s}=9 \mathrm{~cm}$ at the time when the plume has reached a downslope length of $L_{f}=18 \mathrm{~cm}$.

The alongslope velocity $v_{a}$ reaches its maximum within the first 2 Ekman depths and gradually recedes to zero at approximately the height above the bottom where the salinity reaches its ambient value. In case of a stratified interface $\left(\kappa=10^{-6} \mathrm{~m}^{2} \mathrm{~s}^{-1}\right) v_{a}$ shows a 

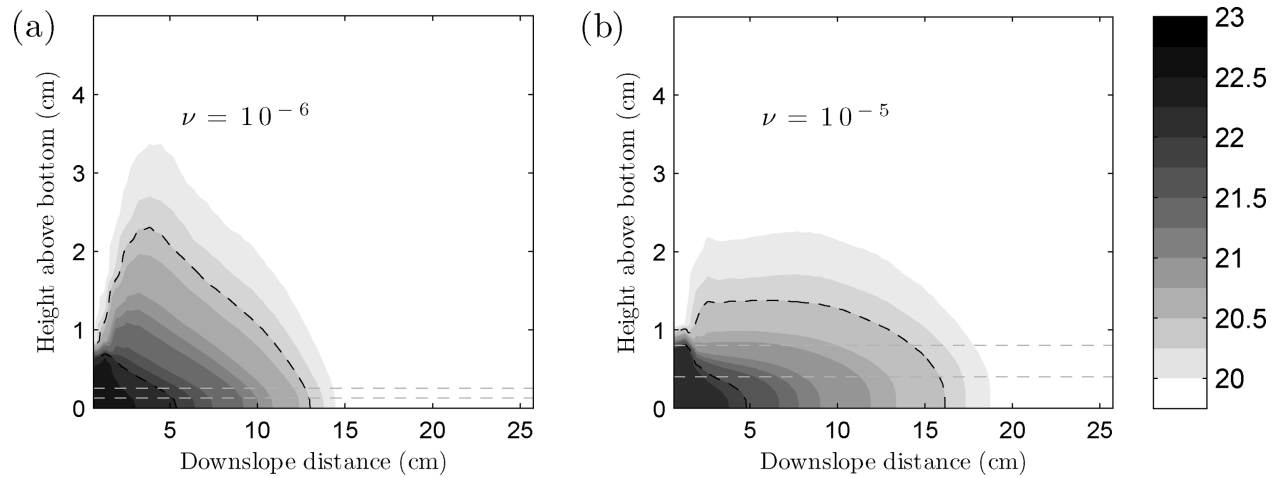

Figure 10. Downslope salinity cross-section of the plume at $144 \mathrm{~s}$ for constant vertical diffusivity $\kappa=10^{-6} \mathrm{~m}^{2} \mathrm{~s}^{-1}$ and varying vertical viscosity $\nu$ (shown in $\mathrm{m}^{2} \mathrm{~s}^{-1}$ ). The section shows the plume thickness relative to the bottom, hence the slope is not shown. The dashed black contours indicate where salinity is $20 \%$ and $80 \%$ of the salinity difference. The dashed horizontal lines mark the height of $H_{e}$ and $2 \times H_{e}$.

smooth transition from its maximum value back to zero high above the core of the plume. The maximum alongslope velocity increases in the stratified case.

The maximum downslope velocity $v_{d}$ reduces as diffusivity decreases (while viscosity remains the same) for the runs shown in Figure 9. The downslope flow does not follow the salinity profile, but remains confined to the bottom boundary layer with a height of about $2 \times H_{e}$. The most notable change in the downslope velocity is the reduction of the return flow (where $v_{d}<0$ ) indicating a gradual disappearance of the interfacial Ekman layer as the stratification of the plume interface broadens. While the velocity profiles in a sharply separated flow match a 'modified Ekman spiral' (shown as $V_{D}$ and $V_{A}$ in Fig. 5) the profiles for a stratified interface resemble the 'classic' Ekman spiral. In the strongly stratified case the downslope transport within the plume behaves as it would within a 1-layer flow; hence density becomes a nearly-passive tracer. This demonstrates that intense diapycnal diffusion can slow or even arrest cascading in the specialised case where vertical diffusivity is increased while vertical viscosity remains constant.

In a further set of runs we investigate the behavior of a diffuse plume (high $\kappa$ ) when the viscosity $\nu$ is also increased. Figure 10 shows cross-sections of the plume in runs that vary the viscosity $v$ from $10^{-6}$ to $10^{-5} \mathrm{~m}^{2} \mathrm{~s}^{-1}$ while the diffusivity is kept constant at $\kappa=10^{-6} \mathrm{~m}^{2} \mathrm{~s}^{-1}$. In these runs the Ekman depth $H_{e}$ ranges from 0.127 to $0.4 \mathrm{~cm}$ (highlighted by horizontal lines in Fig. 10). The Prandtl Number in the vertical is $P r_{v}=O(1)$ in these runs, which makes them directly relevant to observations in a turbulent ocean. The series of plots shows how the plume reacts to a thicker bottom Ekman layer: more of the water that is diffused upward is captured by the cascading flow and transported downslope. After $144 \mathrm{~s}$ the plume has advanced 14.4 and $18.6 \mathrm{~cm}$, respectively. As a consequence of increasing Ekman depth, the plume becomes more elongated and moves faster. This series 
of experiments shows that the slowing effect of increased diapycnal mixing can be offset by increased viscosity because of the increased downslope transport capacity of the cascade. We interpret this as an indication that increased mixing between the plume and the ambient water would generally increase the downslope propagation of a cascade.

\section{Discussion}

We use a 3-D ocean model, POLCOMS, to study cascading on a steep slope. We validate the model against laboratory experiments, compare results with reduced physics models, where applicable, and we go beyond this to investigate the regimes that are difficult to simulate in the laboratory, but which can be encountered in the real ocean.

There is growing understanding of the importance of processes (including cascading) in the bottom boundary layer (BBL) in the shaping of exchanges between the shelves and the deep ocean (e.g. Huthnance et al., 2009). However, modern large-scale ocean and climate models do not resolve small-scale processes occurring in the BBL, in particular on the shelf edges and continental slopes. We feel that the importance of accurately representing BBL processes has so far been somewhat overlooked. A number of attempts have been made to represent the BBL by so-called 'slab' parameterizations (e.g. Beckmann and Döscher, 1997). However, Killworth (2003), reviewing these approaches, highlights the importance of actually resolving the physics within the BBL by saying that " $n o B B L$ 'slab' parameterization can hope to compete with a model that resolves the BBL properly, assuming adequate physics within the layer." The physics in the BBL is characterized by Ekman veering, which was originally derived using a no-slip bottom boundary condition which is commonly used in the study of gravity currents (e.g. Özgökmen and Chassignet, 2002; Wirth, 2009). For the present study we employ the same bottom boundary condition and sufficient vertical resolution to accurately resolve the correct physics in the BBL, thus avoiding the parameterization based on the quadratic drag law. We resolve the BBL by $\approx 10$ computational levels.

Our model set-up is successfully validated against a series of laboratory experiments (Shapiro and Zatsepin, 1997), both quantitatively and qualitatively. The velocity structure and the downslope speed of the cascade also compare very well with the reduced physics model of Shapiro and Hill (1997) in those regimes where the flow has a 2-layer density structure. Our results confirm that nonhydrostatic effects which are not included in POLCOMS and many other ocean models do not affect these models' ability to represent cascading as the magnitude of vertical velocity accelerations is very small compared to the reduced gravity acceleration, even on a slope as steep as $39^{\circ}$. This is in contrast to common belief that nonhydrostaticity should be included in the modeling of processes with a scale of less than about $10 \mathrm{~km}$ (Marshall et al., 1997), but it is consistent with basic principles of geophysical fluid dynamics (Kamenkovich, 1977; Pedlosky, 1987) and confirmed e.g. by the recent comparison of hydrostatic with nonhydrostatic modeling of a river plume on a scale of 1 to $20 \mathrm{~km}$ (McEwan, 2010). However, in the study of small-scale subgrid entrainment 
processes by individual turbulent eddies that are not fully resolved in current models the nonhydrostatic effect could be important.

Another consideration is the potential impact of the centrifugal force on the laboratory experiments. Both POLCOMS and the reduced physics models are geophysical fluid dynamics formulations in which, as is customary, the centrifugal force of rotation is absorbed into an effective gravity. In these models, only the Coriolis force is explicitly retained. Can the centrifugal force be neglected in the laboratory experiments or should it be included as an extra term in the numerical model? Since the gravitational and centrifugal forces are the only driving forces in the problem, it seems natural to gauge the import of the centrifugal force against that of gravity by calculating the ratio of their projections along the bottom slopes, which is $f^{2} r / 4 g \cot \theta$, where $r$ is the distance to the axis of rotation. This ratio is smaller than $5 \%$ in the majority of laboratory experiments and model runs, except 2 experiments where the Coriolis parameter is above $2.5 \mathrm{~s}^{-1}$ and even those were not outliers in our intercomparison of experimental and model results. We therefore argue that it is appropriate to neglect the centrifugal force in this simulation of cascading.

Shapiro and Hill (1997) derived the cascading downslope velocity on a plane slope as $u_{F}=0.2 V_{N o f}$ and the parameterization of the descent rate by Killworth (2001) can be written for our slope angle $\left(\theta=39^{\circ}\right)$ as $u_{F}=\frac{1}{400} \frac{V_{N o f}}{\sin \theta}=0.004 V_{N o f}$. On a conical slope the cascade slows over time (see Fig. 6a), so neither of the two theories is strictly applicable. To compare our model results to these descent rate estimates, we derive the alongslope and downslope velocities as follows. For a fully developed plume, where $L_{f}>6 \mathrm{~cm}$, the downslope velocity is calculated as $u_{F}=\frac{d L_{f}}{d t}$, and the alongslope velocity $V_{N o f}$ is derived using Eq. (1) from the reduced gravity $g^{\prime}$ measured in the model output at a sampling radius $r_{s}=0.75 L_{f}$ (see Fig. 3). An overall average ratio of all downslope and alongslope velocities from the 29 runs shown in Figure $6 \mathrm{a}$ is calculated using linear regression as $\frac{u_{F}}{V_{N o f}}=0.19\left(R^{2}=0.749\right)$, which is surprisingly close to the ratio of $\frac{u_{F}}{V_{N o f}}=0.2$ in the Shapiro and Hill (1997) formula confirming it as a useful tool for providing estimates of cascading parameters from observations.

In a 2-layer regime both the downslope and alongslope flows are confined to a thin layer at the bottom with a thickness of about 2 Ekman depths. This agrees with analytical theories applicable for this regime (Shapiro and Hill, 1997; Wåhlin and Walin, 2001) and is consistent with ocean observations (e.g. Baringer and Price, 1997; Visbeck and Thurnherr, 2009) and laboratory studies (Cenedese et al., 2004). The flow remains a 2-layer structure even for radical changes of viscosity by 2 orders of magnitude. While the plume does not reach the full height of the Ekman layer for higher viscosities, an increase in viscosity causes a thicker plume in real terms. This appears in contrast to Legg et al. (2008) who found that as viscosity increased plume thickness was reduced. Their different numerical configuration which did not fully resolve the Ekman layer could be seen as the reason for a significant influence of uncontrolled numerical viscosity and diffusivity on their results. 
In cases of strong diapycnal mixing, the plume interface blurs significantly and the 2-layer reduced physics model no longer applies. The interface can be defined as blurred when the transitional layer between plume and ambient density is much thicker than the core of the plume itself. This definition is practical to separate different regimes with very different properties.

In the case of a smooth interface the plume diffuses upward and becomes much thicker than the bottom Ekman layer, and much of the dense water moves out of reach of the boundary layer to which the downslope transport remains confined, but is involved in alongslope transport. A comparable situation has been observed in overflow plumes where transport increases downstream due to entrainment (Girton and Sanford, 2003; Matt and Johns, 2007).

The velocity profiles for a 2-layer density structure match the 'modified' Ekman spiral (Shapiro and Hill, 1997, 2003) and show the presence of an interfacial Ekman layer evident by a return flow just above the plume interface. In a flow with a strongly blurred interface the alongslope velocity reacts quickly to the smooth density transition, while the downslope velocity remains confined to the bottom Ekman layer. We cannot confirm whether the downslope velocity would eventually (i.e. after a longer experiment time) adapt its profile to the density structure in the same way as the alongslope velocity. It would be interesting to investigate this difference in adaptation time for dense flows over corrugated bathymetry, such as canyons, where the absolute direction of the downslope and alongslope components of the flow changes frequently. The lack of a return flow in case of a diffuse plume is an indication for the dissolution of the interfacial Ekman layer under the influence of strong diapycnal mixing. This regime and its implications are the subject of ongoing research (Wirth, 2010; Wobus et al., 2010).

Previous studies have considered a sharp interface between the flow or reservoir of dense water and the ambient water for reservoirs or flows that are much thicker than the Ekman depth (e.g. Wåhlin and Walin, 2001; Shapiro and Hill, 2003; Wirth, 2009). They found that a thin layer (of height $h \approx H_{e}$ ) of dense water forms near the bottom and starts to move downslope while the main body of dense water is confined to alongslope motion according to Nof (1983). We show that this is not true for cases where a thick plume (of height $h \gg H_{e}$ ) is formed by the upwards diffusion of dense plume water and the interface is strongly blurred. We find that the downslope flow does not form a thin layer of the order of the Ekman layer height $H_{e}$ and our findings only agree to the extent that downwards propagation is slowed or even arrested.

A thick, but diffused cascade is shown to be strongly affected by the Ekman depth as the slowing effect on downslope motion of high diffusivity $\kappa$ can be compensated for by increased viscosity $\nu$. The results presented in Section $3 \mathrm{e}$ show that the speed of downslope propagation increases in a regime where diffusivity and viscosity are both increased which simulates the effects of increased turbulence. The diffuse plume moves downslope faster because the height of the Ekman layer encompasses most of the plume such that $h \sim O\left(H_{e}\right)$. This is consistent with Figure $4 \mathrm{~b}$ in Shapiro and Hill (1997) which shows that the entrainment process speeds up downslope propagation of the plume in a reduced physics model. The 
acceleration of a cascade due to mixing has practical implications as oceanic turbulence tends to affect diffusivity and viscosity to a comparable degree (as $v$ increases, so does $\mathrm{k}$ and vice versa) and therefore suggests that increased diapycnal mixing in a highly turbulent regime increases downslope transport. This finding helps explain observations in areas of tidally generated turbulence in the Ross Sea (Padman et al., 2009).

\section{Conclusions}

Our results show that the correct resolution of bottom boundary layer physics is critical to successfully model cascading, while nonhydrostaticity is not required to capture the descending plume. The traditional square drag law fails to capture the Ekman veering at the bottom boundary and is shown to insufficiently represent bottom friction, while our 3-D numerical model with a no-slip bottom boundary condition and increased vertical resolution near the bottom was successfully validated against laboratory experiments. The required resolution to fully resolve the BBL is currently impractical for large ocean and climate models, and we therefore call for the development of an improved parametrisation for bottom friction, which includes the Coriolis force and thus captures velocity veering.

Our simulations using POLCOMS highlight the areas of applicability of the previous reduced physics theory, which is only applicable to a 2-layer flow with a sharp interface between the cascading plume and the ambient water. A dense flow with a stratified interface has been investigated with the full physics 3-D numerical model, POLCOMS. Our results show that downslope transport is reduced when the plume interface is strongly diffused, but enhanced in a regime that simulates the effects of increased turbulence where diffusivity and viscosity are both increased.

Acknowledgments. This work was partly funded by NERC's Core Research Programme Oceans 2025 and the EU FP7 MyOceans project. We also thank Andrei G. Zatsepin of the Shirshov Institute of Oceanology, Moscow (Russia) for providing video footage of the laboratory experiments. Finally, we benefited from the comments by two anonymous reviewers who helped to improve the manuscript.

\section{REFERENCES}

Aagaard, K., L. K. Coachman, and E. Carmack. 1981. On the halocline of the Arctic Ocean. Deep-Sea Res. A, 28, 529-545.

Baines, P. G. and S. A. Condie. 1998. Observations and modelling of Antarctic downslope flows: A review, in Ocean, Ice and Atmosphere: Interactions at the Antarctic Continental Margin, S. Jacobs and R. Weiss, eds., Amer. Geophys. Union, 75, 29-49.

Baringer, M. and J. Price. 1997. Mixing and spreading of the Mediterranean outflow. J. Phys. Oceanogr., 27, 1654-1677.

Beckmann, A. and R. Döscher. 1997. A method for improved representation of dense water spreading over topography in geopotential-coordinate models. J. Phys. Oceanogr., 27, 581-591.

Bergamasco, A., V. Defendi, G. Budillon, and G. Spezie. 2004. Downslope flow observations near Cape Adare shelf-break. Antarc. Sci., 16, 199-204. 
Bolaños, R., P. Osuna, J. Wolf, J. Monbaliu, and A. Sanchez-Arcilla. 2007. The POLCOMS-WAM wave-current interaction model: development and performance in the NW Mediterranean, in Maritime Industry, Ocean Engineering and Coastal Resources: Proceedings of the 12th International Congress of the International Maritime Association of the Mediterranean (IMAM), Varna, Bulgaria, 2-6 September 2007, C. Guedes-Soares and P. Kolev, eds. Taylor Francis, 685-691.

Canals, M., R. Danovaro, S. Heussner, V. Lykousis, P. Puig, F. Trincardi, A. M. Calafat, A. Palanques, and A. Sánchez-Vidal. 2009. Cascades in Mediterranean Submarine Grand Canyons. Oceanogr., $22,26-43$.

Carmack, E. 2000. The Arctic Ocean's freshwater budget: Sources, storage and export, in The Freshwater Budget of the Arctic Ocean, NATO Science Series 2 Environmental Security - Vol. 70, L. E. Lewis, E. P. Jones, P. Lemke, T. D. Prowse, and P. Wadhams, eds., Springer, 91-126.

Cenedese, C., J. A. Whitehead, T. A. Ascarelli, and M. Ohiwa. 2004. A dense current flowing down a sloping bottom in a rotating fluid. J. Phys. Oceanogr., 34, 188-203.

Cushman-Roisin, B. and J.-M. Beckers. 2011. Introduction to Geophysical Fluid Dynamics - Physical and Numerical aspects, Academic Press, 2nd ed., 750 pp.

Enriquez, C. E., G. I. Shapiro, A. J. Souza, and A. G. Zatsepin. 2005. Hydrodynamic modelling of mesoscale eddies in the Black Sea. Ocean Dyn., 55, 476-489.

Etling, D., F. Gelhardt, U. Schrader, F. Brennecke, G. Kühn, G. Chabert d'Hieres, and H. Didelle. 2000. Experiments with density currents on a sloping bottom in a rotating fluid. Dyn. Atmos. Oceans, 31, 139-164.

Furevik, T., C. Mauritzen, and R. Ingvaldsen. 2007. The flow of Atlantic water to the Nordic Seas and Arctic Ocean, in Arctic Alpine Ecosystems and People in a Changing Environment, J. B. Ørbæk, R. Kallenborn, I. Tombre, E. N. Hegseth, S. Falk-Petersen, and A. H. Hoel, eds., Springer, $123-146$.

Geyer, F., I. Fer, and T. Eldevik. 2009. Dense overflow from an Arctic fjord: Mean seasonal cycle, variability and wind influence, Cont. Shelf Res., 29, 2110-2121.

Girton, J. B. and T. B. Sanford. 2003. Descent and modification of the overflow plume in the Denmark Strait. J. Phys. Oceanogr., 33, 1351-1364.

Gordon, A. L., A. H. Orsi, R. Muench, B. A. Huber, E. Zambianchi, and M. Visbeck. 2009. Western Ross Sea continental slope gravity currents. Deep-Sea Res. II, 56, 796-817.

Griffiths, R. W. 1986. Gravity currents in rotating systems. Annu. Rev. Fluid Mech., 18, 59-89.

Haney, R. L. 1991. On the pressure gradient force over steep topography in sigma coordinate ocean models. J. Phys. Oceanogr., 21, 610-619.

Hill, A. E., A. J. Souza, K. Jones, J. H. Simpson, G. Shapiro, R. McCandliss, H. Wilson, and J. Leftley. 1998. The Malin cascade in winter 1996. J. Mar. Res., 56, 87-106.

Holt, J. T. and I. D. James. 2001. An s-coordinate density evolving model of the northwest European continental shelf, Part 1: Model description and density structure. J. Geophys. Res., 106, 1401514034.

2006. An assessment of the fine-scale eddies in a high-resolution model of the shelf seas west of Great Britain. Ocean Model., 13, 271-291.

Holt, J., S. Wakelin, and J. M. Huthnance. 2009. Down-welling circulation of the northwest European continental shelf: A driving mechanism for the continental shelf carbon pump. Geophys. Res. Lett., 36, L14602.

Huthnance, J. M. 1995. Circulation, exchange and water masses at the ocean margin: the role of physical processes at the shelf edge. Progr. Oceanogr., 35, 353-431.

2009. Accelerating dense-water flow down a slope. J. Phys. Oceanogr., 39, 1495-1511.

Huthnance, J. M., J. T. Holt, and S. L. Wakelin. 2009. Deep ocean exchange with west-European shelf seas, Ocean Sci., 5, 621-634. 
Ivanov, V. V., and P. N. Golovin. 2007. Observations and modeling of dense water cascading from the northwestern Laptev Sea shelf. J. Geophys. Res., 112, C09003.

Ivanov, V. V., G. I. Shapiro, J. M. Huthnance, D. L. Aleynik, and P. N. Golovin. 2004. Cascades of dense water around the world ocean. Progr. Oceanogr., 60, 47-98.

Kamenkovich, V. M. 1977. Fundamentals of Ocean Dynamics, Elsevier, 249 pp.

Killworth, P. D. 1977. Mixing of the Weddell Sea continental slope. Deep-Sea Res., 24, 427-448.

- 1983. Deep convection in the World Ocean. Rev. Geophys., 21, 1-26.

2001. On the rate of descent of overflows. J. Geophys. Res., 106, 22267-22275.

2003. Inclusion of the bottom boundary layer in ocean models, in Proceedings of the

13th 'Aha Huliko'a Hawaiian Winter Workshop on Near Boundary Processes and their Parameterization, 2003, P. Müller, ed., 177-185. URL http://www.soest.hawaii.edu/PubServices/ 2003pdfs/Killworth.pdf.

Lane-Serff, G. F. 2009. Overflows and Cascades, in Encyclopedia of Ocean Sciences, J. H. Steele, K. K. Turekian, and S. A. Thorpe, eds., Academic Press, Oxford, 265-271.

Lane-Serff, G. F. and P. G. Baines. 1998. Eddy formation by dense flows on slopes in a rotating fluid. J. Fluid Mech., 363, 229-252.

2000. Eddy formation by overflows in stratified water. J. Phys. Oceanogr., 30, 327-337.

Legg, S., Y. Chang, E. P. Chassignet, G. Danabasoglu, T. Ezer, A. L. Gordon, S. Griffies, R. Hallberg, L. Jackson, W. Large, T. Özgökmen, H. Peters, J. Price, U. Riemenschneider, W. Wu, X. Xu, and J. Yang. 2009. Improving oceanic overflow representation in climate models: the Gravity Current Entrainment Climate Process Team. Bull. Amer. Meteor. Soc., 90, 657-670.

Legg, S., L. Jackson, and R. W. Hallberg. 2008. Eddy-resolving modeling of overflows. Geophys. Monogr. Ser., 117, 63-81.

Marshall, J., C. Hill, L. Perelman, and A. Adcroft. 1997. Hydrostatic, quasi-hydrostatic, and nonhydrostatic ocean modeling. J. Geophys. Res., 102, 5733-5752.

Matt, S. and W. Johns. 2007. Transport and entrainment in the Red Sea outflow plume. J. Phys. Oceanogr., 37, 819-836.

McEwan, R. 2010. Non-hydrostatic effects in a propagating large-scale river plume, in 14th Biennial Challenger Conference for Marine Science, Southampton, 6 - 9 September 2010, Book of Abstracts, 93. URL http://www.challenger2010.org.uk/programme.

McWilliams, J. C., E. Huckle, and A. F. Shchepetkin. 2009. Buoyancy effects in a stratified Ekman layer. J. Phys. Oceanogr., 39, 2581-2599.

Melling, H. and E. Lewis. 1982. Shelf drainage flows in the Beaufort Sea and their effect on the Arctic Ocean pycnocline. Deep-Sea Res. A, 29, 967-985.

Nof, D. 1983. The translation of isolated cold eddies on a sloping bottom. Deep-Sea Res. A, 30, 171-182.

Orsi, A. H. and C. L. Wiederwohl. 2009. A recount of Ross Sea waters. Deep-Sea Res. II, 56, 778-795.

Özgökmen, T. M. and E. Chassignet. 2002. Dynamics of two-dimensional turbulent bottom gravity currents. J. Phys. Oceanogr., 32, 1460-1478.

Padman, L., S. Howard, A. H. Orsi, and R. D. Muench. 2009. Tides of the northwestern Ross Sea and their impact on dense outflows of Antarctic Bottom Water. Deep-Sea Res. II, 56, 818-834.

Pedlosky, J. 1987. Geophysical Fluid Dynamics, Springer, 2nd ed., 728 pp.

Price, J. F., M. O. Baringer, R. G. Lueck, G. C. Johnson, I. Ambar, G. Parrilla, A. Cantos, M. A. Kennelly, and T. B. Sanford. 1993. Mediterranean outflow mixing and dynamics. Science, 259, 1277-1282.

Rudels, B. 2009. Arctic Ocean Circulation, in Encyclopedia of Ocean Sciences, J. H. Steele, K. K. Turekian, and S. A. Thorpe, eds., Academic Press, Oxford, 211-225. 
Rudels, B., L. G. Anderson, and E. P. Jones. 1996. Formation and evolution of the surface mixed layer and halocline of the Arctic Ocean. J. Geophys. Res., 101, 8807-8821.

Rudels, B., H. J. Friedrich, and D. Quadfasel. 1999. The Arctic Circumpolar Boundary Current. Deep-Sea Res. II, 46, 1023-1062.

Salat, J., M. A. Garcia, A. Cruzado, A. Palanques, L. Arín, D. Gomis, J. Guillén, A. de León, J. Puigdefábregas, J. Sospedra, and Z. R. Velásquez. 2002. Seasonal changes of water mass structure and shelf slope exchanges at the Ebro Shelf (NW Mediterranean). Cont. Shelf Res., 22, 327-348.

Sánchez-Vidal, A., C. Pasqual, P. Kerhervé, A. Calafat, S. Heussner, A. Palanques, X. Durrieu de Madron, M. Canals, and P. Puig. 2008. Impact of dense shelf water cascading on the transfer of organic matter to the deep western Mediterranean basin. Geophys. Res. Lett., 35, L05605.

Schauer, U. and E. Fahrbach. 1999. A dense bottom water plume in the western Barents Sea: downstream modification and interannual variability. Deep-Sea Res. I, 46, 2095-2108.

Shapiro, G. I. and A. E. Hill. 1997. Dynamics of dense water cascades at the shelf edge. J. Phys. Oceanogr., 27, 2381-2394.

2003. The alternative density structures of cold/saltwater pools on a sloping bottom: The role of friction. J. Phys. Oceanogr., 33, 390-406.

Shapiro, G. I., J. M. Huthnance, and V. V. Ivanov. 2003. Dense water cascading off the continental shelf. J. Geophys. Res., 108, 3390-3409.

Shapiro, G. I., and A. G. Zatsepin. 1997. Gravity current down a steeply inclined slope in a rotating fluid. Ann. Geophys., 15, 366-374.

Smith, P. C. 1975. A streamtube model for bottom boundary currents in the ocean. Deep-Sea Res., 22, 853-873.

Steele, M. and T. Boyd. 1998. Retreat of the cold halocline layer in the Arctic Ocean. J. Geophys. Res., 103, 10419-10435.

Sutherland, B. R., J. Nault, K. Yewchuk, and G. E. Swaters. 2004. Rotating dense currents on a slope. Part 1. Stability. J. Fluid Mech., 508, 241-264.

Turner, J. S. 2010. The melting of ice in the Arctic Ocean: The influence of double-diffusive transport of heat from below. J. Phys. Oceanogr., 40, 249-256.

Visbeck, M. and A. Thurnherr. 2009. High-resolution velocity and hydrographic observations of the Drygalski Trough gravity plume. Deep-Sea Res. II, 56, 835-842.

Wåhlin, A. K. and G. Walin. 2001. Downward migration of dense bottom currents. Environ. Fluid Mech., 1, 257-279.

Wakelin, S., J. Holt, and R. Proctor. 2009. The influence of initial conditions and open boundary conditions on shelf circulation in a 3D ocean-shelf model of the North East Atlantic. Ocean Dyn., 59, 67-81.

Wirth, A. 2009. On the basic structure of oceanic gravity currents. Ocean Dyn., 59, 551-563.

2010. Turbulent fluxes in oceanic gravity currents. Geophys. Res. Abstr., 12, EGU2010-1566.

Wobus, F., G. I. Shapiro, M. A. M. Maqueda, and J. M. Huthnance. 2010. Numerical simulations of dense water cascading laboratory experiments: a sensitivity study, in, 14th Biennial Challenger Conference for Marine Science, Book of Abstracts, 69. URL http://www.challenger2010 .org.uk/programme.

Wollast, R. and L. Chou. 2001. The carbon cycle at the ocean margin in the northern Gulf of Biscay. Deep-Sea Res. II, 48, 3265-3293.

Received: 22 December, 2010; revised: 20 September, 2011. 